\title{
Towards a Complexity-Friendly Policy: Breaking the Vicious Circle of Equilibrium Thinking in Economics and Public Policy
}

\author{
Flaminio Squazzoni
}

\begin{abstract}
This chapter aims to discuss certain limitations of the dominant equilibrium thinking in policy and explore more complexity-friendly alternatives. If societies and markets are viewed as complex, non-equilibrium systems, understanding nonlinear, adaptive and evolving patterns emerging from agent behaviour in network structures is fundamental for policy purposes. This requires improved realism of the behavioural and social foundations on which policies are based. We must also reconsider the mantra of incentivisation, institutional design and the top-down regulation that typically dominates conventional policy. Recent cases of financial market regulation and health policies can help us to understand the importance of looking at the subtle ways in which people or organisations behave when exposed to social influence, and pre-existing social norms and network externalities. Changing the current policy narrative and exploring complexity-friendly concepts, instruments and methods requires a shift of focus of policy-making from forecast and prediction of system equilibrium in order to understand and manage complex social systems better.
\end{abstract}

\section{Introduction}

These are hard times for policy-making. Today, policy makers are asked to cope with serious challenges, such as financial instability, environmental sustainability, demographic change and migration. All of this is occurring in periods of increasing interdependence between explosive technological innovation, real-time communication and new social behaviour. The implications of this interdependence are difficult to predict and control by anyone (see for example [53]). Extreme events, such as local wars, financial meltdown, humanitarian crises and environmental disasters, continue to capture the headlines dramatically affecting public opinion. Policy makers are condemned to cope with these events by referring instruments which

\footnotetext{
F. Squazzoni $(\bowtie)$

Department of Economics and Management, University of Brescia, Via San Faustino, 74/B 25122 Brescia, Italy

e-mail: flaminio.squazzoni@unibs.it
}

(C) The Author(s) 2017

J. Johnson et al. (eds.), Non-Equilibrium Social Science and Policy, Understanding Complex Systems, DOI 10.1007/978-3-319-42424-8_9 
look at a world of order, equilibrium and predictability, where problems can be compartmentalised into specific domains.

However, recent evidence indicates that these problems are interconnected and that extreme events might be the result of certain inherent dynamics of social systems rather than the consequence of external or individual causes [30]. For example, the Global Risks report released in January 2011 by the World Economic Forum argued that extreme events are due to systems' interdependence in determining global vulnerability.

For example, let us consider the 'water-food-energy' nexus. In this case, the rapid rise of global population and growing prosperity are putting unsustainable pressure on natural resources, with shortages, high volatility and dramatic increase of resource prices. This in turn provokes social and political instability, also due to migration pressures, geopolitical conflicts and environmental damage. Price volatility and competition for resources create fiscal pressures in advanced economies and possibly social instability in emerging economies. Under these situations, economic disparities lead to short-term responses in production and consumption that undermine long-term sustainability in a vicious circle.

Another example would be the 'illegal economy' nexus, which is also nurtured by global governance failure and growing economic disparity. Increasing opportunities for illegal activities, also thanks to the availability of advanced information and communication technologies, are all contributing to the fragility of states. This is caused by increasing corruption, eroding trust in public institutions and fewer resources for the welfare state and public goods. This also generates a series of disadvantages for legitimate economic activity by increasing transaction and capital costs and pressurising disadvantaged competitors to participate in corrupt practices. This in turn erodes social capital and the moral and legal bases of market societies and also traps some countries in cycles of poverty and instability [54].

All these examples indicate that the behaviour of social systems is neither random, as if God were playing dice with the world, nor entirely regular. Social systems are complex evolving systems whose behaviour depends upon links between many agents, all with heterogeneous beliefs, preferences, information and social structural positions that interact in subtle ways over significant space and time scales [26]. If policies do not consider these factors, interventions may miss their mark and create or reflect a world that does not exist [19].

This chapter aims to reconsider the current state-of-the-art of policy making in view of these new challenges. The second section discusses the limitations of the theory of human behaviour behind conventional policy and the weakness of methods and instruments generally used for policy-making. First, behavioural research indicates that policies assume that people behave in ways they do not. Secondly, policies only take a top-down approach, i.e. policy inputs versus decision makers, without considering the existence of a horizontal dimension, i.e. individuals are embedded in a social context that endogenously reacts to policy inputs through peer-to-peer effects.

Furthermore, there are certain methodological problems that are intrinsic to the anti-complexity approach of the dominant paradigm. Policies are a deductive 
exercise based on presupposed knowledge more than an experimental endeavour. As such they are informed at best only by econometric estimations of longitudinal data on individual aggregates. These data incorporate a simplistic notion of social aggregates as the mere sum of individual data, such as states, characteristics or choices of individuals, households or organisations. These black-box data do not take into account all the complex interaction effects characterising social systems, and they overestimate past trends and underestimate the likelihood of extreme events (e.g. Room [39]; Geyer [24]; Squazzoni [47]).

The third section presents some examples of problems in economic and public health policies. They show that policies can be ineffective if they underestimate the effect of complex networks, social norms and socially constructed choices. Looking at the way in which individuals or organisations are connected helps to contemplate more complexity-friendly approaches that could increase policy effectiveness.

Finally, the last section looks at the prospects and challenges of complexityfriendly policy. The argument is that a new research-policy interface is required, with new scientific methods and instruments in the policy domain, but also a shared capability of involving stakeholders in a common endeavour that points to understanding and management more than prediction and external regulation.

\section{The Mechanistic Approach of Conventional Policy}

Conventional policy typically follows a mantra of incentivisation, institutional design and top-down control. This is part of the intellectual background of the Newtonian, mechanistic, prediction and context free-oriented tradition of science, organisation, management and policy [19]. The concept follows the belief that observers, policy makers in our case, are outside the reality they want to change and deal with closed systems with given equilibrium states, which can be known in advance and modified through a linear cause-effect manipulation, e.g. policy intervention. According to this view, policy takes place 'off-line' and outside the system of interest (e.g. Finch and Orillard [22]). Policy is not seen as a component of a system behaviour interacting with other components such as individuals or organisations, and policy is not jointly engaged in a constructive process that determines the way systems behave $[17,47]$.

Policies typically start from predicting people's behaviour and end up by setting up appropriate incentives, promulgating regulations or providing information that are designed to alter individual behaviour towards predefined goals. For instance, by modifying the price of certain goods or services or subsiding certain industry sectors, policy makers underline decision makers' preferences in order to change the system equilibrium to a predefined level.

When a government passes a new regulation that extends or reduces detention for a given crime or prescribes anti-discrimination regulations in private companies, the crime rate is expected to decline along with inequality in the workplace. This is because people are expected to respond predictably and rationally to manipulated 
cost-benefit options. In the first instance, introducing a negative incentive is expected to modify the cost-benefit perception by delinquents who are supposed to rationally evaluate whether to commit a crime or not. In the second case, the prescription is expected to induce human resource managers to hire disadvantaged minorities and majorities more equally in order to avoid lawsuits by employers or applicants.

Unfortunately, this does not always happen for a variety of reasons. First, decision makers do not have a unique cost-benefit decision framework. Recently, behavioural research indicated that decision makers are not rational and are more heterogeneous than predicted by rational choice theory. This is because decisions are biased by various sources of bounded rationality (e.g. backward-looking heuristics, selective attention and habit) and subject to various social pressures (e.g. social imitation and conformism) [43]. Evidence suggests that people make biased choices, are past-driven and follow simple behavioural heuristics even when they have perfect information and have to decide from only a few options $[12,13]$. Not only can decision makers be irrational, they also have heterogeneous beliefs, preferences and threshold choices that are hard to predict. This indicates that even well-designed policy options could provoke unpredictable responses if behaviour is not considered.

For example, many crimes are perpetrated under emotional circumstances and the probability of committing a crime is not determined by the same cost-benefit analysis for everyone. Secondly, there are unforeseen contextual and systemic factors that might lead to unintended consequences. Consider the case of the weak impact of sexual harassment policies on reducing gender bias in organisations [52]. In this case, while these policies were originally designed to reduce gender bias in the workplace, they actually strengthened traditional discrimination norms (e.g. they reinforced males' prejudices that females are protected by law because they are less competent), increased paternalistic stereotypes in organisations and induced females to correspond to the typical male stereotype of victims in order to take advantage of these norms. Here the policies backfired as they did not consider the implicit signalling effect of regulations and how these signals would have interacted with pre-existing contextual factors.

However, behavioural research would indicate that, especially when social outcomes depend on decentralised cooperation by individuals or organisations, the 'bounds' of decision makers' rationality could even allow individuals to overcome their own self-interest [9]. Indeed, public good provision in competitive settings depends on the existence of social norms which make individuals pursue social rather than egoistic aims [27]. If we consider that people's behaviour is a complex mix of self-interested rationality and moral motivations, in some circumstances adding incentives or imposing external regulation can backfire by eroding social norms and mutual obligations that have been spontaneously generated in specific social contexts (e.g. [10]).

This would undermine one of the strongest ideas of conventional policy, i.e. that policies are outside-in, 'neutral' interventions. Policies are never neutral as they always enact a constructive process of reflexivity, which depends on preexisting social relationships and moral and normative frameworks through which 
decision makers have interpreted them. As argued by Bowles and Polanía-Reyes [11], policies enact interpretations of policy makers' intentions by decision makers and induce people to frame the decision environment. For example, incentivisation policies might induce decision makers to frame the context as a cost-benefit, rational choice problem, thus nurturing selfishness which may erode pre-existing good behaviour [46]. Furthermore, policies can compromise a control-adverse individual's sense of autonomy, dramatically affecting the process by which individuals learn new preferences and are socially digested through peer-to-peer social mechanisms (e.g. mutual observation of reactions, imitation and information externalities among decision makers). Therefore, in certain cases, pushing incentives could lead to defection, excessive opportunism or myopic attitudes by decision makers, which could in turn be detrimental to the public good.

This would indicate that policy failures are not due to the size of the state or the magnitude of the resources, but to the intellectual framework in which policy is conceived [34]. It is worth noting that this framework is instrumental in defending the public image of politicians. Under strong political competition at all government levels, politicians need to show accountable, immediate and measurable achievements to manage public opinion. This reinforces the tendency of conceiving policy as a top-down control exercise and nurtures the misplaced expectation by policy makers that scientists, experts and consultants can provide silver-bullet solutions.

This attitude also pays off traditional views and old-boyism in political life. The same attitude is also embodied in the state-of-mind of most economics, law or engineering-trained public officials and technocrats. Their position and role often lead them to overemphasis external regulation against context-dependent factors and self-organisation processes typical of complex social systems.

Believing that people are rational and predictable and the idea of policy as a top-down regulation exercise go hand-in-hand with policy makers general lack of interest in the possible advantages of behaviourally informed experimental approaches to test policy options.

In this respect, the recent establishment of behavioural 'nudge' policy units by the US and UK governments is a significant progress. The nudge idea is that, rather than assuming that people are fully rational, with a potentially predictable set of preferences that could be altered by manipulating incentives, individuals can be induced to make more rational choices simply by providing additional information that can tweak the decision context [50]. This idea has robust experimental evidence that suggests the use of experimental procedures to test policy options before implementing them [43], for example by submitting different types of information to randomised control and treatment groups of individuals. This indicates that an experimental 'epistemic culture' has started to penetrate the political inner circles. Yet, as we will see below, this is not sufficient. 


\section{The Underestimation of Complex Network Effects in Economic and Health Policies}

Some key examples of specific limitations of conventional policy are the regulation of financial markets implemented by the US government and EU market authorities after the global financial crisis of 2008 and the typically static approach of public health policy. In both cases, the problem was the underestimation of the complexity of these systems. Specifically they indicated the the lack of understanding of how things are connected to each other and how they interact together in a dynamic network structure. In the first case, the presence of complex connections between banks and financial institutions was not considered. In the second, the traditional view of one-cause-one-disease-one-treatment did not look at the biological and social network determinants of diseases.

\subsection{Network Implications for the Regulation of Financial Markets}

After the systemic implications of the collapse of Lehman Brothers in September 2008 and the huge amount of taxpayers' money used to bail out hundreds of banks worldwide, the problem of how system risk can be mitigated in financial markets has been at the top of the agenda for policy makers and market authorities. To answer this, the so-called 'macroprudential regulation' and the Basel III principles have followed a recipe based on the idea of external controllability, i.e. setting up regulations that increase bank capital requirements and extending the regulation authorities' margin in order to manoeuvre when necessary.

By considering the role of financial networks in endogenously generating system risk, recent studies on financial networks have shown that this policy is not sufficient or even counterproductive [51]. For example, using an empirical dataset on the USD 1.2 trillion FED emergency loans programme during 2008-2010, Battiston et al. [6] built a DeptRank indicator that mapped the links between financial institutions in terms of financial dependence (e.g. dept distribution and equity investment relations) and, similar to PageRank and other feedback centrality indicators, measured the impact of a distressed node (e.g. a bank) across the whole network. Results showed that systemic risk is a network property of the financial system and not the property of a single financial agent or an exogenous factor. They found that a group of 22 financial institutions, which received most FED funds, were so deeply connected that each of the nodes could be a potential source of network vulnerability. This implies that a systemic default of the market could also be triggered by small dispersed shocks in the network.

Thurner and Poledna [51] used the same rank to analyse the impact of transparency on the interbank liability network. They built two simulation scenarios. The first one mimicked the current situation in that banks did not know the systemic 
impact of other banks Credits were traded with the conventional inter-bank offer rate. The second one was built to test a regulation scheme that allowed banks to know the DebtRank value of their counterpart and trade first with less risky partners. The results showed that by making bank's systemic risk values transparent, the financial network restructured its shape by distributing risk better throughout the system and minimising the chance of a systemic failure. Furthermore, this did not negatively affect credit volume or trading volume in the real economy.

Poledna and Thurner [37] built certain simulation scenarios where they tested the implications of imposing a negative incentive on markets, i.e. a risk transaction tax imposed on any transaction that was proportional to the expected systemic losses that the transaction could bring according to the DebtRank. Empirical data of nation-wide interbank liabilities was used to calibrate their model. By comparing a scenario (1) where banks ignored their contribution to systemic risk and traded credits in a way similar to the practice today with (2) one where the systemic risk tax was imposed, they showed that the tax was capable of reducing the probability of financial collapse and minimising the size of potential cascading failures. The tax was capable of inducing financial networks to restructure in less risky ways, and without lowering the system's credit volume.

They also compared their tax with the Tobin tax, which many analysts and politicians suggest as a solution to this problem. The results showed that the latter could reduce risk in the same way as the former, but only by drastically reducing the credit volume and without restructuring the network. It is worth noting that current market regulation causes banks with the highest systemic risk to be subsided while the majority of taxes are imposed on those with the lowest level of risk.

To sum up, these studies provide a more realistic picture of the complexity of financial markets, by emphasising the importance of considering their real structure. This is one of the main sources of market opacity which impedes understanding and regulation. They suggest that (negative and positive) incentives and regulations can be more effective if they can induce markets to self-organise themselves in less systemically risky ways. The adoption of data-driven, real time network metrics and visualisations, which are both available and are not difficult to implement, could help policy makers and market authorities to explore more adaptive, context-based policies [42]. Obviously, the challenge here is to overcome the nested interests that link big financial institutions and political power towards perpetuating conventional thinking.

\subsection{The Network Medicine Approach to Public Health Policy}

Health policies have traditionally followed the idea that diseases are individual constructs, mostly one-cause-related, which can be compartmentalised and treated with single targeted therapies. These therapies are usually experimentally assessed through randomised clinical trials and analysis of cost-effectiveness performed exclusively at population level. Recent studies in health have suggested that a 
systemic approach may help to identify the genetic and proteomic networks which explain specific diseases clusters. This approach allows us to consider the relevance of the social environment in generating disease risks [3]. Furthermore, complex systems analysis techniques have been recently used as a different approach not only in research but also for planning health care policies.

The idea that complex information such as the distribution of disease in a population, could be better recognised as systemic pattern tracing back to the end of the twentieth century. Indeed, studies have shown that diseases are not independent of each other as they aggregate and co-occur in the same individual due to a common network background [32]. Furthermore, diseases are strongly influenced by the way individuals are socially connected $[14,17]$.

For instance, in the Framingham Heart Study, obesity was evaluated in 12,067 participants assessed periodically over 30 years. Christakis and Fowler [15] found that obesity tends to cluster in particular social communities and that friends have a higher effect on the risk of obesity than genes do. This means that social ties might influence an individual's perception of the acceptability of obesity and thus food consumption. As a result, network externalities can contribute to generate unpredictable patterns of the obesity epidemic in the population. This also explains why weight-loss interventions that provide peer support are more successful than those that do not, independent of the magnitude of the specific health programmes.

A similar effect of social network externalities on health was found in studies evaluating smoking [16], food choices [36], alcohol consumption [25, 35] sexually transmitted diseases $[5,8,23,40]$ In these cases, the social determinants of lifestyles and habits, pre-existing social norms and social influence pressures explain the diffusion of unhealthy behaviours and the related diseases.

On the one hand, these findings indicate that the typical single-minded focus on one-cause-disease and single-target drugs that characterise the modern view of medicine can be misleading. On the other hand, it also calls for reconsideration of the dominant health policy thinking, which is too deterministic and not equipped to take into account the interconnected nature of many diseases as well as their social determinants [4]

Furthermore, looking at specific networks as determinants of health or disease allows us to reconsider the relationship between genes and environment. For instance, by analysing data on genetic structure in a large scale population provided by the National Longitudinal Study of Adolescent Health and the Framingham Heart Study, Fowler et al. [23] showed that the genetic structure may be less determined by reproduction constraints (e.g. kinship or geographical proximity of mates) than by social ties. Indeed, ceteris paribus, they found that people's friends have similar traits on a genotypic level as if individuals were 'metagenomic' with respect to their social ties. This means that disease can derive from a complex interplay between genes and social environment, in which the latter is expected to play a crucial role which was not empirically observed in past research. For instance, genetic properties of friendship groups could predispose or prevent individuals against certain diseases and confer fitness advantages or disadvantages that are also fundamental for gene selection. 
These results have important implications for designing and improving health care services. First, significant outcomes could be achieved if we extend the outlook and the interventions from individuals or aggregates to social networks. Rather than the micro level or macro level, looking at the meso level becomes essential as we can observe how biological and social networks interact. Furthermore, by intervening on the social environment we could help to exploit social network externalities, which could be less costly than traditional programmes. If we look at diseases as complex networks including genetic, proteomic and metabolic sub-networks, as well as interconnections among biological, social and environmental systems, we could exploit the synthetic function of social ties on these network diseases. Indeed, social networks may act on a set of interrelated nodes at different hierarchical levels (e.g. genetic, proteomic and metabolic levels), thus triggering (positive or negative) effects on the entire biological network. Therefore, mapping these networks effects and simulating the potential impact of therapies or interventions considering possible space-time externalities could provide valuable insights to test options and inform policies.

Finally, this approach also suggests we should reconsider the traditional costeffectiveness approach in health policy. Given that network externalities can trigger the cumulative effects of a therapeutic or preventive intervention by directly targeted individuals to their social ties, mapping and measuring the systemic effects of interventions can help us to evaluate outcomes of certain interventions more systematically [44]. Indeed, certain interventions or treatments which are economically impractical if considered at the individual level alone could become effective once network externalities at are considered.

\section{Challenges Towards a Complexity-Friendly Policy}

Complexity-friendly policy is the application of complexity science approaches, methods and instruments to policy making. The global challenges we have to cope with call for a collaborative effort by scientists, policy makers and stakeholders in innovating policy concepts, methods and instruments. A new research-policy interface is needed that connects science with stakeholders' vision, knowledge and priorities. The limitations of linear and basic science-technology relations when accounting for the intricate interplay between science and technology [21], must also be considered for the science-policy relation.

The lack of an interface between science, policy and stakeholders has been suggested by many analysts as being one of the major obstacles for coping with economic, social and environmental challenges. This is because it rewards inertia and incremental change in policy and nurtures a lack of understanding of the imperfect, experimental nature of science by policy makers and the public opinion [1, 29, 41, 49]. Given the intrinsic complexity of human affairs, a complexityfriendly experimental policy can help to impose the idea that policy options must be empirically and/or artificially tested before to be implemented. In this respect, as 
already said, the recent establishment of behavioural 'nudge' policy units by the US and UK governments is significant progress.

Yet, it is not enough. The idea of nudges must be considered more seriously, as not only can policy makers can nudge people towards better informed choicesin social life people also nudge each other. The 'behavioural' side of these new policies must be complemented by a 'social' side [48]. Adding network simulation and computational modelling of complex social systems, where individuals or organisations interact in complex ways, is needed to embody the idea of social complexity in policy making. This would also help us to complement the limitations of a randomised controlled trial approach of standard experimental tests by considering contextual and social factors This would extend the typical scale limitations of any experimental procedure and complement them for unfeasible experimental procedures. These complexity instruments could also provide a virtual test-bed for policy options on the large scale and help to scale up interventions.

The time is ripe for policies to capitalise on the new universe of technological innovation in digitalisation and computing in every sphere of life, including science, markets and social relations [30]. We also need to increase our use of advanced computational and data mining instruments which allow us to map the structure and behaviour of the social systems of interest more inductively and experimentally. The advantages of this approach have recently been suggested for developing complex behavioural and network indicators that look at systemic effects in humanitarian and environmental disasters, energy policies and financial markets $[1,18,30]$. This can help us to contemplate new types of collaboration with stakeholders at all levels, from sharing data and domain knowledge to coordinated implementation and distributed management of change processes.

Exploiting advanced complexity-friendly computational instruments would also help us to redefine the individual unit focus of cost-effectiveness that dominates policy implementation and evaluation. This is a critical point addressed by network medicine to study human disease but also has implications also for public policy in general. First, computer simulation and real-time data that integrate various levels of analysis could add a context-based dimension and map possible network externalities when testing policy options. Secondly, it could help us to include scenario visualisations of expected outcomes on more complex space and time scales. This would extend the limits of individual cost-effectiveness analysis to include network externalities and systemic effects. Reconsidering the efficacy and economic sustainability of more systemic, network-informed options could help us to consider interventions that would not even be contemplated when looking solely at an individual level [44]

Finally, we need a complexity-friendly policy narrative. While the conventional narrative is based on a top-down, outside-in control mantra, the new narrative should be based on simple ideas, drawn from complexity studies in a variety of fields, from markets and organisations to urban development [2, 7, 33].

The first is the 'less-is-more' concept. In each system, whether natural, technological or social, a recurrent finding of complexity studies is that there is no linear relation between cause and effect, so that the magnitude of input and expected output 
is not proportional [33]. This is because of the influence of initial conditions, the presence of interaction and systemic factors and the emergence of threshold effects and tipping points that are endogenously generated by the system of interest when it reacts to the external input [20].

This must also be the case for the policy-system relations. For example, let us consider the failure of economic theory driven, outside-in development programmes in under-developed countries from the 1950s [31], the success of small-scale, selforganised, asset-based community development (ABCD) initiatives in the 1990s in the US [45] or the famous case of the positive deviance approach in solving childhood malnourishment in Vietnamese villages, which also had relevant business and management implications [28].

In each case, we found the disproportionate effect of external manipulation on system outcomes. In all positive cases, more than the magnitude of the policy input, the secret of the success was intensively collaborating with stakeholders in all stages of the policy process, adapting policy plans to system behaviour and setting up sequential, bottom-up processes of improvement [38]. For example, this was the real lesson of the positive deviance policy by Save the Children in Vietnam. In this case, after years of failures of outside-in, top-down programmes, the situation of childhood malnourishment was significantly improved simply by discovering and amplifying existing good practices developed spontaneously in certain villages. The same was found in asset-based community development initiatives in the US in the 1990s, where exploiting existing assets and internal forces more than establishing top-down programmes which generated positive externalities on the communities involved, such as social capital, self-confidence and trust among people Thus solving one problem led to solving others relatively spontaneously [45]. This was also the lesson that Albert O. Hirschmann drew from the failures of the big development programmes in the Third world in the 1950s when he suggested the importance of working on bottom-up complementarities [31].

This naturally leads to the second idea, that of working on 'conducive' conditions and exploiting bottom-up forces of social systems. The State-market dichotomy in which the State sometimes plays an active role with big programmes and sometimes leaves everything to market forces, leads to underestimating the strength of social norms and social systems self-organising in reaching collective results. The challenge here is to explore the positive role of pre-existing domain conditions, including social norms, in order to accompanying positive self-organisation processes by encouraging diversity, heterogeneity and leveraging ground strengths [19]. More than a prediction lever, here what can make the difference is transforming policy into constructive, adaptive processes of bottom-up management [47]. This could also help us to understand when top-down incentives and external push can make a difference and when they are detrimental.

Acknowledgements The author would like to thank Alessandra Marengoni for useful comments on a previous version. The usual caveat applies. 
Open Access This chapter is distributed under the terms of the Creative Commons Attribution 4.0 International License (http://creativecommons.org/licenses/by/4.0/), which permits use, duplication, adaptation, distribution and reproduction in any medium or format, as long as you give appropriate credit to the original author(s) and the source, provide a link to the Creative Commons license and indicate if changes were made.

The images or other third party material in this chapter are included in the work's Creative Commons license, unless indicated otherwise in the credit line; if such material is not included in the work's Creative Commons license and the respective action is not permitted by statutory regulation, users will need to obtain permission from the license holder to duplicate, adapt or reproduce the material.

\section{References}

1. Allcott, H., Mullainathan, S.: Behavior and energy policy. Science 327, 1205-1205 (2010)

2. Axelrod, R., Cohen, M.: Harnessing Complexity. Organizational Implications of a Scientific Frontier. The Free Press, New York (1999)

3. Barabási, A.L.: Network medicine - From Obesity to the Diseasome. N. Engl. J. Med. 357(4), 404-407 (2007)

4. Barabási, A.L., Gulbahce, N., Loscalzo, J.: Network medicine: a network-based approach to human disease. Nature 12, 56-68 (2011)

5. Bassett, E., Moore, S.: Social capital and depressive symptoms: the association of psychological and network dimensions of social capital with depressive symptoms in Montreal, Canada. Soc. Sci. Med. 86, 96-102 (2013)

6. Battiston, S., Puliga M., Kaushik, R., Tasca P., Caldarelli, G.: DebtRank: too central to fail? financial networks, the FED and systemic risk. Sci. Rep. 2, 541 (2012)

7. Batty, M.: The New Science of Cities. The MIT Press, New York (2013)

8. Bearman, P.S., Moody J., Stovel, K.: Chains of affection: the structure of adolescent romantic and sexual networks. Am. J. Sociol. 110(1), 44-91 (2004)

9. Bianchi, F., Squazzoni, F.: Agent-based models in sociology. WIREs Comput. Stat. 7(4), 294 $306(2015)$

10. Bowles, S.: Policies designed for self-interested citizens may undermine 'the moral sentiments': evidence from economic experiments. Science 320(5883), 1605-1609 (2008)

11. Bowles, S., Polanía-Reyes, S.: Economic incentives and social preferences: substitutes or complements? J. Econ. Perspect. 50(2), 368-425 (2012)

12. Bravo, G., Takács, K., Squazzoni, F.: (2015) Intermediaries in trust: indirect reciprocity, incentives, and norms. J. Appl. Math. 2015. Article ID 234528. doi:10.1155/2015/234528

13. Camerer, C.F.: Behavioral Game Theory. Princeton University Press, Princeton, NJ (2003)

14. Chan, S.Y., Loscalzo, J.: The emerging paradigm of network medicine in the study of human disease. Circ. Res. 111, 359-374 (2012)

15. Christakis, N.A., Fowler, J.H.: The spread of obesity in a large social network over 32 years. N. Engl. J. Med. 357(4), 370-379 (2007)

16. Christakis, N.A., Fowler J.H.: The collective dynamics of smoking in a large social network. N. Engl. J. Med. 358(21), 2249-2258 (2008)

17. Christakis, N.A., Fowler, J.H.: Social network sensors for early detection of contagious outbreaks. PLos ONE 5, e12948 (2010)

18. Cioffi-Revilla, C.: Seeing it coming: a complexity approach to disasters and humanitarian crises. Complexity 19(6), 5-13 (2014)

19. Colander, D., Kupers, R.: Complexity and the art of public policy. solving society's problems from the bottom-up. Princeton University Press, Princeton, NJ (2014)

20. Durlauf, S.N.: What should policy makers know about economic complexity? Wash. Q. 21, 157-165 (1998) 
21. Edquist, C. (ed.): Systems of Innovation. Technologies, Institutions and Organizations. Pinter, London (1997)

22. Finch, J., Orillard, M.: Introduction: the scope of complexity and its implications for policy. In: Finch, J., Orillard, M. (eds.) Complexity and the Economy. pp. 1-14. Edward Elgar, Cheltenham (2005)

23. Fowler, J.H., Settle, J.E., Christakis, N.A.: Correlated genotypes in friendship networks. PNAS 108(5), 1993-1997 (2011)

24. Geyer, R.: Can complexity move UK policy beyond 'evidence-based policy making and the 'audit culture'? Applying a 'complexity cascade' to education and health policy. Polit. Stud. 60, 20-43 (2012)

25. Giabbanelli, P., Crutzen, R.: An agent-based social network model of binge drinking among Dutch adults. J. Artif. Societies Soc. Simul. 16(2), 10 (2013). http://jasss.soc.surrey.ac.uk/16/ 2/10.html

26. Gilbert, N., Bullock, S.: Complexity at the social science interface. Complexity 19(6), 1-4 (2014)

27. Gintis, H.: The Bounds of Reason. Game Theory and the Unification of the Behavioral Sciences, 2nd edn. Princeton University Press, Princeton, NJ (2013)

28. Goldstein, J., Hazy, J.K., Lichtenstein, B.B.: Complexity and the Nexus of Leadership. Leveraging Nonlinear Science to Create Ecologies of Innovation. Palgrave MacMillan, New York (2010)

29. Gormley, W.T. Jr.: From science to policy in early childhood education. Science 333, 978-981 (2011)

30. Helbing, D.: Globally networked risks and how to respond. Nature 497, 51-59 (2013)

31. Hirschman, A.O.: The Strategy of Economic Development. Yale University Press, New Haven (1958)

32. Marengoni, A., Angleman, S., Melis, R., Mangialasche, F., Karp, A., Garmen, A., Meinow, B., Fratiglini, L.: Aging with multimorbidity: a systematic review of the literature. Ageing Res. Rev. 10(4), 430-439 (2011)

33. Miller, J.H., Page, S.E.: Complex Adaptive Systems: An Introduction to Computational Models of Social Life. Princeton University Press, Princeton, NJ (2007)

34. Ormerod, P.: Positive Linking. How Networks Can Revolutionise the World. Faber \& Faber, London (2012)

35. Ormerod, P., Wiltshire, G.: Binge drinking in the UK: a social network phenomenon. Mind Soc. 8(2), 135-152 (2009)

36. Pachuki, M.A., Christakis, N.A.: Social network concordance in food choice among spouses, friends, and siblings. Am. J. Public Health 101(11), 2170-2177 (2011)

37. Poledna, S., Thurner, S.: DebtRank-transparency: controlling system risk in financial networks. Scientific Reports, 3, 1888 (2013)

38. Rhodes, M.L., Murphy, J., Muir, J., Murray, J.A.: Public Management and Complexity Theory. Richer Decision-Making in Public Services. Routledge, London (2011)

39. Room, G.: Complexity, Institutions and Public Policy. Agile Decision-Making in a Turbulent World. Edward Elgar, Cheltenham (2011)

40. Rosenquist, J.N., Fowler, J.H., Christakis, N.A.: Social network determinants of depression. Mol. Psychiatry 16, 273-281 (2011)

41. Schenkel, R.: The challenge of feeding scientific advice into policy making. Science 330, 1749-1751 (2010)

42. Schweitzer, F., Fagiolo, G., Sornette, D., Vega-Redondo, F., Vespignani, A., White, D.R.: Economic networks: the new challenges. Science 325(5939), 422-425 (2009)

43. Shafir, E. (ed.): The Behavioral Foundations of Public Policy. Princeton University Press, Princeton (2013)

44. Smith, K.P., Christakis, N.A.: Social networks and health. Annu. Rev. Sociol. 34, 405-429 (2008)

45. Squazzoni, F.: Local economic development initiatives from the bottom-up: the role of community development corporations. Community Dev. J. 44(4), 500-514 (2009) 
46. Squazzoni, F., Bravo, G., Takács, T.: Does incentive provision increase the quality of peer review? an experimental study. Res. Policy 42(1), 287-294 (2013)

47. Squazzoni, F.: A social science-inspired complexity policy: beyond the mantra of incentivization. Complexity 19(6), 5-13 (2014)

48. Squazzoni, F.: The "Reign of Mystery": have we missed something crucial in our experimental work on social norms? In: Xenitidou, M., Edmonds, B. (eds.) The Complexity of Social Norms, pp. 177-188. Springer, Heidelberg (2014)

49. Sutherland, W.J., Spiegelhalter, D., Burgman, M.A.: Twenty tips for interpreting scientific claims. Nature 503, 335-337 (2013)

50. Thaler, R.H., Sustein, C.R.: Nudge: improving decisions about health, wealth, and happiness. Penguin Books, London (2009)

51. Thurner, S., Poledna, S.: Elimination of system risk in financial networks by means of a systemic risk transaction tax. arXiv:1401.8026 (2013)

52. Tinkler, J.E.: How do social harassment policies share gender beliefs? an exploration of the moderating effects of norm adherence and gender. Soc. Sci. Res. 42, 1269-83 (2013)

53. Vespignani, A.: Predicting the behavior of techno-social systems. Science 325, 425-428 (2009)

54. World Economic Forum: Global Risks 2011, 6th edn. World Economic Forum Report, Geneva (2012) 